\title{
Türkiye'de Devlet Karayollarında Kaza Oranlarının ve Kaza Örüntüsünün Analizi
}

\author{
Murat ÖZEN ${ }^{1}$ \\ Fikret ZORLU $\mathbf{U}^{2}$
}

Öz

Bu çalışmada Türkiye'de 2009 ile 2013 yılları arasında devlet karayolları kesimlerinde istatistiksel ve coğrafi yöntemler kullanılarak kaza analizleri yapılmıştır. Çalışmanın coğrafi analizler aşamasında global Moran's I değeri hesaplanarak kaza oranlarının mekânsal korelasyonunun olup olmadığına bakılmıştır. Kazaların hangi yol kesimlerinde daha yüksek oranda gerçekleştiğini tespit etmek için milyar taşıt-km başına düşen ölümlü ve/veya yaralanmalı (ÖY) kaza sayısı göstergesi kullanılmıştır. Bu kesimlerin coğrafi dağılımı incelendiğinde dağınık (kümelenmemiş) bir örüntü ortaya çıkmaktadır. Ulaşım ve trafik araştırmaları yazınında taşıt hacmi kaza sayısını açıklayan en önemli etkeni olarak gösterilmektedir. Bu çalışmada kaza oranları incelenerek taşıt yoğunluğu dışında pek çok etkenin açıklayıcı olabileceği iddia edilmiştir.

Anahtar Kelimeler: Trafik kazaları, devlet karayolları, kazaların coğrafi analizi.

\begin{abstract}
An Analysis of Crash Rates and the Crash Pattern on State Highways in Turkey

This study comprises a statistical and geographic analysis of traffic crashes on road segments of state highways in Turkey for the period of 2009 to 2013. At the geographic analysis stage, Global Moran's I value is used to measure the level of spatial concentration of crashes. Fatal and injury (FI) crashes per billion vehicle-kilometer traveled (VKT) is selected as a measure of exposure to identify state highway segments with higher crash rates. The geographic distribution of the road segments with higher rates shows a dispersed (not clustered) pattern. Researches in transportation and traffic literature showed that traffic volume is the most effective explanatory factor of traffic crashes. This research argues that many other factors may have significant influence on crash rates.
\end{abstract}

Keywords: Traffic crashes, state highways, geographic analysis of the crashes.

\footnotetext{
Not: Bu yaz1

- Yayın Kurulu'na 23.01.2017 günü ulaşmıştır. 30.01.2018 günü yayımlanmak üzere kabul edilmiştir.

- 30 Kasım 2018 gününe kadar tartışmaya açıktır.
}

- DOI: $10.18400 /$ tekderg.308318

1 Mersin Üniversitesi, İnşaat Mühendisliği Bölümü, Mersin - ozen.murat@mersin.edu.tr

2 Mersin Üniversitesi, Şehir ve Bölge Planlama Bölümü, Mersin - fikretzorlu@yahoo.com 


\section{GİRIŞ}

Trafik kazaları, dünyadaki başlıca ölüm nedenleri arasında sekizinci sırada bulunmaktadır, 15-29 yaş aralığındaki genç nüfus için ise başlıca ölüm nedenidir [1,2]. Dünyada trafik kazalarında yılda bir milyondan fazla kişi ölmekte ve bu kazaların toplam maliyeti milyar dolar seviyesine ulaşmaktadır [3]. Mevcut eğilimlerin devam etmesine izin verilirse yakın gelecekte trafik kazaları ölüm sebeplerinde beşinci sıraya yükselecektir [2]. Bu rakamlar, trafik kazalarının dünyada ciddi bir güvenlik ve sağlık sorunu olarak ele alınmasının gerekliliğini ortaya koymaktadır. Türkiye'de de benzer bir durum gözlenmektedir. 2015 yılında trafik kazalarında 7 bin 530 kişi ölmüş ve 304.000 kişi yaralanmıştır [4]. Bu kazalar, Türkiye'de Gayri Safi Yurt İçi Hasıla ürününün yaklaşık \%1,1'i düzeyinde maddi zarara mal olmaktadır [2]. Artan nüfus ve gelir seviyesine paralel olarak özel otomobil sahipliği, tüketime bağlı olarak ticaret ve ulaşım araçlarının kullanımı da giderek artmaktadır. Son 10 yıl içinde trafiğe kayıtlı taşıt sayısı \%79,4 artmıştır. Buna rağmen, kişi başına düşen taşıt sayısı hala gelişmiş ülkelerin gerisindedir. 2015 yılı verilerine göre Türkiye' de 1.000 kişi başına düşen taşıt sayısı 254'tür [5,6]. OECD tarafından 2016 yılında yayınlanan verilere göre bu değer İngiltere'de 568, Fransa'da 665, Almanya'da 681 ve ABD'de 862'dir [7].

Literatürde trafik güvenliğini analiz etmek ve değerlendirmek için çeşitli ölçütler kullanılmaktadır. Milyon kişi başına ölüm, bir kişinin trafik kazasında ölme riskini ifade etmektedir. Fakat bu oran tek başına ülkelerin trafik güvenlik risklerini karşılaştırmak için anlamlı sonuçlar vermemektedir; burada taşıt sayısı, taşıt kullanım sıklığı, yoğunluğu gibi etkenlerin de dikkate alınması gerekmektedir. Trafik güvenliği riskini değerlendirmek için milyar taşıt $\mathrm{km}$ başına ölüm sayısı en uygun gösterge olarak kabul edilmekte ve ülkeler bu göstergeye göre karşılaştırılmaktadır [3]. Güvenilir taşıt-km verilerinin olmadığı durumlarda trafiğe kayıtlı taşıt başına ölüm sayısı bir alternatif bir gösterge olarak kullanılabilir [7]. Türkiye'de trafik kazalarında milyon kişi başına düşen ölüm sayısı 2015 yılı için 96'dır [4,6]. $\mathrm{Bu}$ sayı AB-28 ülkeleri için ortalama 51 ve ABD için 102 olarak yayınlanmıştır [7,8]. Görüldüğü gibi, Türkiye'de 1.000 kişi başına $\mathrm{AB}$ ülkeleri kadar taşıt düşmemesine rağmen milyon kişi başına düşen ölüm sayısı daha yüksektir. En güvenilir karşılaştırma ölçütü olan milyar taşıt-km başına düşen ölüm sayısına bakıldığında, 2015 yılı verilerine göre Türkiye'de bu değerin 66,5 olduğunu görmekteyiz. Türkiye bu değeri 2023 yılı öncesinde 10'un altına düşürmeyi hedeflemektedir [9]. AB-28 ülkeleri için ortalama değer yayınlanmamasına rağmen bazı ülkelere ait değerler karşılaştırma yapmak için kullanılabilir. İngiltere, Almanya ve Fransa'daki oranlar sırasıyla 3,6, 4,6 ve 5,9 olarak yayınlanmıştır. Dünyada kişi başına düşen taşıt sayısı en yüksek ülke olan ABD'nde bu değer 6,7'dir [7].

Yukarıda sunulan rakamlar trafik güvenliğinin Türkiye'de ciddi bir sorun olduğunu ortaya koymaktadır. Literatürde bu konudaki ulusal düzeydeki çalışmalar oldukça sınırlıdır. Mevcut çalışmaların çoğunluğunda lokal düzeyde kara noktaların analizi yapılmıştır. Bu şekilde tespit edilen kaza yoğunlaşma analizleri noktasal bazda çözümlere olanak sağlamaktadır ancak yol kesimi bazında çözümler için yeterli olamamaktadır. Bu eksikliği gidermek amacıyla, bu çalışmada Türkiye devlet karayolu ağında 2009-2013 yılları arasında gerçekleşen ölümlü ve yaralanmalı kazaların yol kesimleri bazında dağılımları ve bunların taşıt hacmi, taşıt-km ve yol özellikleri ile ilişkisi irdelenmiştir. Ulusal düzeyde karayolu yatırım politika ve önceliklerinin belirlenmesi için talep analizi kadar güvenlik analizinin de yapılması önem taşımaktadır. Bu amaçla, kaza analizi ile trafik güvenliğinin en fazla sorunlu 
(kaza riskinin yüksek) olduğu yol kesimleri saptanmıştır. Bu bulgulardan yararlanılarak devlet karayollarında yeni yatırım ve iyileştirme çalışmaları yapılabilir.

$\mathrm{Bu}$ çalışma sırasıyla aşağıdaki bölümlerden oluşmaktadır. Bölüm 2'de karayolu trafik güvenliği ile ilgili geçmiş literatür kısaca özetlendikten sonra, Bölüm 3'de Türkiye'deki ulusal trafik kaza verileri incelenmiştir. Bölüm 4'de çalışma kapsamında kullanılan veri ve yöntemler anlatılmıştır. Bölüm 5 çalışma sonuçları ortaya konduktan sonra Bölüm 6' da sonuç ve öneriler tartışılmıştır.

\section{LITERATÜR ÖZETI}

Karayolu trafik kazalarının güvenlik ve risk analizleri hakkında kapsamlı bir literatür bulunmaktadır. Bu çalışmalar küresel veya ulusal düzeydeki kapsamlı değerlendirmelerden kaza düzeyindeki adli incelemelere kadar uzanmaktadır. Bu çalışmaların odak noktaları tüm taşıtlardan, kamyonlar, otobüsler, otomobiller, iki tekerlekli motosikletler ve bisikletler ve yayalar gibi belirli bir kullanıcı gruplarına kadar farklılık göstermektedir. Tüm bu çabalar ulaşım sistemlerindeki riski en aza indirerek sistem kullanıcılarının güvenliğini arttırmayı ve çevreye verilen zararları en aza indirmeye yönelik karar ve yatırımlara girdi sağlayacak bilgi ve değerlendirmeleri sunmayı hedeflemektedir.

Trafik kazalarındaki yaralanmaların şiddetlerini etkileyen risk faktörlerini belirleyebilmek için çeşitli yöntem ve yaklaşımlar kullanılmaktadır [10]. Bu yöntemler arasında logit modeller [11,12] ve sıralı probit regresyon modelleri [13-15] gibi çok değişkenli regresyon yaklaşımları sıklıkla tercih edilmektedir. Bu tür regresyon modellerinin en önemli avantajı kazaların yaralanma şiddetini etkileyebilecek birçok faktörü aynı anda analiz edilebilmesidir [16]. Fakat bu tür modeller, trafik özellikleri (Yıllık Ortalama Günlük Trafik, hız sınırı ve trafik kontrolü vb.), sürücü özellikleri (yaş, cinsiyet, eğitim seviyesi, kaza ve ceza geçmişi, madde etkisi altında ve dikkat dağıtıcı kullanım, yardımcı cihaz kullanımı vb.), kaza özellikleri (kaza konumu, çarpışma tipi, kazaya karışan araçların sayısı ve türü, kazaya neden olan eylem vb.), çevresel faktörler (hava durumu, arazi tipi, 1şık durumu vb.), zamansal faktörler (kaza günü, saati ve mevsimi vb.), karayolu geometrik özellikleri (yol sınıfı, yüzey koşulları, yatay ve düşey dönemeçlerin varlığı, bölünmüş/bölünmemiş yol vb.) gibi kaza düzeyinde çok detaylı veriye ihtiyaç duymaktadır [11,17].

Türkiye'de trafik kaza verileri çoğunlukla bütünleşik olarak yayınlanmaktadır. Bu istatistikler, toplam kaza sayısını, kazaya karışan araçların sayısını ve türünü, toplam ölüm ve yaralanma sayılarını içermektedir. Ulusal düzeyde detaylı kaza seviyesinde veri olmaması nedeniyle, trafik güvenliğindeki bölgesel ve taşıt tipine bağlı değişimler ayrıntılı olarak incelenememiştir. Sadece Erdoğan [18], 2001 ve 2006 yılları arasında il düzeyinde trafik kaza ve ölüm sayılarındaki farklılıkları incelemeye çalışmıştır. Çalışmada trafikteki gerçek haraketliliği tam olarak yansıtmamasına rağmen, il düzeyinde taşıt-km verisi eksikliği nedeniyle, kişi başına ve trafiğe kayıtlı taşıt sayısına düşen kaza ve ölüm sayıları hesaplanmıştır. Elde edilen sonuçlar, yüksek kaza ve ölüm oranlarının rastgele dağılmadığını ve İstanbul, Ankara ve Antalya’yı birbirlerine bağlayan illerde kümelendiğini göstermiştir.

Öte yandan, yerel ve bölgesel çalışmalar için belirli düzeye kadar kaza düzeyinde detaylı veri elde etmek mümkündür. En sık rastlanan yerel kaza verileri kazanın coğrafi koordinatlarını ve tarihini, kazaya karışan araç sayısı ve türlerini, ölü ve yaralı sayılarını içermektedir. Kaza 
noktasının coğrafi koordinatları bu veriler arasında olduğundan yakın geçmişteki çalışmaların çoğunluğu kaza sıcak noktalarının mekânsal ve zamansal analizine odaklanmaktadır [19-24]. Modelleme aşamasında kaza düzeyinde yeteri kadar detaylı veri kullanan iki yerel çalışma dikkat çekmektedir. Bu çalışmaların ilkinde 2008 ile 2013 yılları arasında Kars ve Erzurum'daki kazaların şiddetini etkileyen faktörleri ortaya çıkarmak için multinominal logit analizi kullanılmıştır [25]. Bu dönemde meydana gelen 47.387 kazadan rastgele seçilen 11.771 kazanın şiddeti ölümlü, yaralanmalı ve maddi hasarlı olmak üzere üç kategoriye ayrılmıştır. Çalışma sonuçları 65 yaş üstü sürücülerin, ilköğretim mezunu sürücülerin, tek aracın karıştığı kazaların, yaya geçitlerindeki kazaların, il yolları, devlet karayolları ve otoyollardaki kazaların kaza şiddetini arttırdığını göstermiştir. Bir diğer çalışmada otobüs kazalarındaki hasar şiddetini etkileyen faktörleri araştırmak için sıralı probit modeli kullanılmıştır [26]. 2002 yılında Türkiye'de meydana gelen 3.467 otobüs kazasından elde edilen verilerin kullanıldığı çalışmada hasarsız, az hasar, orta hasar ve yüksek hasar olmak üzere dört hasar seviyesi kullanılmıştır. Elde edilen sonuçlar gece veya kötü hava şartlarında meydana gelen kazaların hasar şiddetini arttırdığını göstermiştir.

Türkiye'de karayolu ağında kesimlerin trafik güvenliği seviyelerini karşılaştırmalı olarak inceleyen bir çalışma bulunmamaktadır. Bu çalışmanın bu eksikliği gidermesi ve katkı sağlaması amaçlanmaktadır. Literatürde kazaların mekânsal/coğrafi dağılımlılarını inceleyen pek çok çalışmada farklı parametre ve faktörler (nüfus, gelir, iklim, şehiriçi/şehir dışı ayrımı, taşıt sahipliği vd.) incelenerek sorunun çözümüne yönelik bulgular ortaya çıkarılmıştır [2730]. Türkiye'de detaylı çalışmaların yapılamamasının en önemli nedenlerinden bir tanesi yeterli detayda istatistiksel verilerin bulunamamasıdır. Bu sorunu aşmak için belirli koridorlar bazında kaza raporlarına ulaşılması, saha çalışması yapılması ve buna bağlı analizlerin gerçekleştirilmesi gerekmektedir.

\section{ULUSAL KAZA VERILERI}

Tablo 1'de sunulan son 15 yıllık dönemde, Türkiye nüfusu 65,0 milyondan 78,7 milyona (\% 21 artış), ehliyetli sürücü sayısı 15,0 milyondan 27,5 milyona (\%83 artış) ve kayıtlı taşıt sayısının 8,6'dan 20 milyona (\%133 artış) yükseldiği görülmektedir [5-6,31]. Bu süreçte toplam taşıt-km düzenli bir şekilde artarak 51,7'den 113,2 milyara (\%119 artış) yükselmiştir [32]. Türkiye 2015 yılından itibaren uluslararası düzeyde tavsiye edilen kaza sonrası 30 günlük gözlem süresini uygulamaya başlamıştır. 2015 yılına kadar yalnızca kaza noktasında meydana gelen ölüm ve yaralanmalar kayıt altına alınırken, 2015 yılından itibaren kaza anını takip eden 30 günlük süre içerisinde meydana gelen ölümler ve yaralanmalar kaza istatistiklerinde gösterilmeye başlanmıştır. Bu nedenle 2015 yılı öncesi ve sonrasındaki trafik kaza istatistiklerini karşılaştırırken veri toplama sürecindeki bu değişime dikkat edilmelidir. 2015 yılında trafik kazalarında meydana gelen ölümlerin \%50,9'u (3.831) kaza noktasında \%49, 1'i (3.699) ise kaza sonrasındaki 30 gün içerisinde meydana gelmiştir. Bu değerler kaza sonrasındaki süreçte en az kaza noktasındaki kadar ölümün meydana geldiğini ve veri toplama sürecindeki bu gelişmenin önemini açıkça ortaya koymaktadır. Bu sayede Türkiye'de trafik güvenliği problemi artık daha gerçekçi bir şekilde incelenebilecek ve diğer ülkelerle daha güvenilir karşılaştırmalar yapılması mümkün olacaktır.

Veri toplama sürecindeki yukarıda bahsedilen değişiklik nedeniyle, 2002 yılı verileriyle 2014 yılı verileri (2015 yerine) karşılaştırılmıştır. Tablo 1'de 2002 ile 2014 yılları arasında ölü 
sayısının düzenli bir şekilde 4.093'den 3.524'e düştüğü görülmektedir. Bundan daha önemlisi, milyar taşıt-km başına ölü sayısının 79,2'den 34,2'ye ciddi bir azalma gösterdiği görülmektedir. Türkiye İstatistik Kurumu (TÜIK) y1l içerisinde meydana gelen ölümlü ve yaralanmalı kazaları ayrı ayrı yayınlamamaktadır. Bunun yerine ölümlü ve/veya yaralanmalı (ÖY) kazalar ve bu kazaların sonucunda meydana gelen ölüm ve yaralanmalar birlikte yayınlanmaktadır. Milyar taşıt-km'deki ÖY kaza sayısı bazı dalgalanmalar göstererek 1.273 'den 1.636'ya yükselmiştir. Benzer şekilde milyar taşıt-km'deki yaralı sayıs1 2.253'ten 2.768 'e yükselmiştir. Görüldüğü gibi milyar taşıt-km'deki ölü sayısı azalmakta iken, ÖY kaza ve yaralı sayısı ise artmaktadır.

Tablo 1. 2002 - 2015 yılları arasında Türkiye'deki ölümlü ve yaralanmalı kaza istatistikleri [31]

\begin{tabular}{|c|c|c|c|c|c|c|c|c|}
\hline \multirow[b]{2}{*}{ Y1l } & \multirow{2}{*}{$\begin{array}{l}\text { Kayıtlı } \\
\text { Taşıt }\end{array}$} & \multirow{2}{*}{$\begin{array}{l}\text { Milyon } \\
\text { Taşıt-km }\end{array}$} & \multirow{2}{*}{$\begin{array}{c}\text { ÖY } \\
\text { Kaza }\end{array}$} & \multirow[b]{2}{*}{ Ölü } & \multirow[b]{2}{*}{ Yaral1 } & \multicolumn{3}{|c|}{ Milyar Taş1t-km'de } \\
\hline & & & & & & $\begin{array}{c}\text { ÖY } \\
\text { Kaza }\end{array}$ & Ölü & Yaralı \\
\hline 2002 & 8.655 .170 & 51.664 & 65.748 & 4.093 & 116.412 & 1.273 & 79,2 & 2.253 \\
\hline 2003 & 8.903 .843 & 52.349 & 67.031 & 3.946 & 118.214 & 1.281 & 75,4 & 2.258 \\
\hline 2004 & 10.236 .357 & 57.767 & 77.008 & 4.427 & 136.437 & 1.333 & 76,6 & 2.362 \\
\hline 2005 & 11.145 .826 & 61.129 & 87.273 & 4.505 & 154.086 & 1.428 & 73,7 & 2.521 \\
\hline 2006 & 12.227 .393 & 64.577 & 96.128 & 4.633 & 169.080 & 1.489 & 71,7 & 2.618 \\
\hline 2007 & 13.022 .945 & 69.609 & 106.994 & 5.007 & 189.057 & 1.537 & 71,9 & 2.716 \\
\hline 2008 & 13.765 .395 & 69.771 & 104.212 & 4.236 & 184.468 & 1.494 & 60,7 & 2.644 \\
\hline 2009 & 14.316 .700 & 72.432 & 111.121 & 4.324 & 201.380 & 1.534 & 59,7 & 2.780 \\
\hline 2010 & 15.095 .603 & 80.124 & 116.804 & 4.045 & 211.496 & 1.458 & 50,5 & 2.640 \\
\hline 2011 & 16.089 .528 & 85.495 & 131.845 & 3.835 & 238.074 & 1.542 & 44,9 & 2.785 \\
\hline 2012 & 17.033 .413 & 93.989 & 153.552 & 3.750 & 268.079 & 1.634 & 39,9 & 2.852 \\
\hline 2013 & 17.939 .447 & 99.431 & 161.306 & 3.685 & 274.829 & 1.622 & 37,1 & 2.764 \\
\hline 2014 & 18.828 .721 & 102.988 & 168.512 & 3.524 & 285.059 & 1.636 & 34,2 & 2.768 \\
\hline $2015^{*}$ & 19.994 .472 & 113.274 & 183.011 & 7.530 & 304.421 & 1.616 & 66,5 & 2,687 \\
\hline
\end{tabular}

* Türkiye 2015 yılı itibariyle kaza sonrası 30 günlük gözlem süresini uygulama koymuştur.

$\mathrm{Bu}$ eğilimin sebeplerinden bir tanesi Karayolları Genel Müdürlüğü tarafindan uygulanan bölünmüş yol politikası olabilir. Bölünmüş devlet karayollarının uzunluğu 2002 ile 2014 yılları arasında 5.573 km'den 21.099 km'ye yükseltilmiştir. Böylece 2014 yılı sonu itibariyle devlet karayollarının \%63,1'i bölünmüş yol haline getirilmiştir. Bu durum kazalardaki karşıdan gelen taşıtla kafa kafaya çarpışmaları ve bunun sonucu meydana gelen ölümleri azaltmıştır. Bu hipotezin sınanması için bu çalışmada sadece belirli bir düzeyde analizler yapılmıştır. Bölünmüş ve bölünmemiş yollar arasında kaza oranı açısından fark olup olmadığı ve en fazla kaza yaşanan yol kesimlerinin belirli bölgelerde yoğunlaşıp yoğunlaşmadığı tespit edilmiştir. Ancak, detaylı ve daha güvenilir bulgulara varabilmek için 
son 5 yıl içinde inşa edilmiş olan bölünmüş yollarda önce-sonra analizinin yapılması ve her bir yıl için karşılaştırmalı kaza oranı değişimlerinin incelenmesi gerekmektedir.

Tablo 1'de görüldüğü gibi genel olarak artma eğilimde olan milyar taşıt-km'deki ÖY kaza sayısında, 13 Temmuz 2010 tarihinde bölünmüş devlet karayollarında hız sınırının 90 $\mathrm{km} / \mathrm{s}$ 'den $110 \mathrm{~km} / \mathrm{s}$ 'e yükseltilmesinin de katkısının olduğu muhtemeldir. Bu iki durum birlikte incelendiğinde; hız sınırının yükseltilmesinin daha fazla kazaya sebep olduğu ama yolların bölünmüş olması sebebiyle bu kazaların şiddetinin ve bunun sonucunda meydana gelen ölümlerin azaldığı yorumu yapılabilir. Bu bir ön tespit ve hipotez olup, her bir kaza için detaylı analiz yapılması durumunda bölünmüş yollardaki kaza şiddetinin etkisi ortaya çıkarılabilir. Bu konuda daha güvenilir bir tespit yapabilmek için, hız sınırının artmasının kazaların oranına ne düzeyde etkisi olduğuna yönelik nokta, kesim ve yıl bazında ayrı bir çalışma yapılması gerekmektedir.

\section{VERI VE YÖNTEM}

Türkiye'de ÖY kazalar trafik polisi ve jandarma birimleri tarafindan sorumluluk alanlarına göre raporlanır ve saklanır. Maddi hasarlı kazalar ise ilgili sürücüler tarafından rapor edilir ve toplanan veriler trafik sigortası bilgi merkezi veri tabanında saklanır. Bu çalışma kapsamında 2009-2013 yılları arasında trafik polisi sorumluluğu altındaki bölgelerde meydana gelen tüm ÖY kazalara ait veriler kullanılmıştır. Bu kazalar çalışma süresince Türkiye'de meydana gelen tüm ÖY kazaların \%83,9'una karşılık gelmektedir. Elde edilen veriler her bir kaza için kaza tarihini, kaza noktasının coğrafi koordinatlarını, kazaya karışan araçların türünü ve sayısını, meydana gelen ölüm ve yaralanmaların sayısını içermektedir. $\mathrm{Bu}$ veri trafik polisi sorumluluğu altındaki tüm kazaları içerdiği için şehiriçi sokak ve caddelerde, il yollarında, devlet karayollarında ve otoyollarda meydana gelen kazaları içermektedir. $\mathrm{Bu}$ sürede Türkiye'de trafik polisi sorumluluğundaki bölgelerde toplam 566.337 ÖY kaza meydana gelmiştir. Bu kazaların 264.918'ine $(\% 46,8)$ tek araç, 301.419 'una $(\% 53,2)$ ise birden fazla araç karışmıştır. Verisi alınan kazaların yaklaşık \% 1,5'i hatalı koordinat kodlamalarından dolayı çalışma kapsamından çıkarılmıştır.

Çalışmanın ilk aşamasında kazaların coğrafi koordinatları ArcGIS 10.0 ortamında 100 metre içerisindeki en yakın yola (sokak, cadde, il yolu, devlet karayolu veya otoyol) atanmıştır. Kaza koordinatları atanırken cihazların hassasiyet düzeyleri nedeniyle gerçek noktadan sapmalar olabilmektedir. Bu nedenle 100 metre hata payı dikkate alınarak her bir yol tipi üzerindeki ÖY kaza sayısı, ölüm ve yaralanmalar bulunmuştur. Fakat Türkiye'de güvenilir taşıt-km verisi sadece devlet karayollarında düzenli yayınlandığı için diğer yol türleri çalışma kapsamından çıkarılmıştır. Şekil 1'de Türkiye'deki devlet karayolu ağ1 görülmektedir. Çalışmanın ikinci aşamasında ise Dünya Sağlık Örgütü’nün de ülkeler arası karşılaştırma yapmak için tanımladığı aşağıdaki denklem kullanılarak her bir devlet karayolu kesimi için milyar taşıt-km'deki ÖY kaza sayısı, ölü sayısı ve yaralı sayısı hesaplanmıştır. Trafik kazalarının ender görülen olaylar olması sebebiyle beş yılın kazaları ve taşıt-km değerleri birleştirilerek bu oranlar hesaplanmıştır. Böylece her bir kesime yeteri miktarda kaza düşme olasılığı arttırılmış ve kesimler arasında kaza sayılarındaki ufak değişimlerin kaza oranlarını ciddi oranda arttırmasının önüne geçilmiştir. Elde edilen sonuçlar ArcGIS 10.0 ortamında tematik haritalar şeklinde görüntülenerek yorumlanmıştır. 
$R_{\mathrm{i}}=10^{9} * \frac{C_{i}}{V K T_{i}}$

$\mathrm{Bu}$ denklemde, $i$ devlet karayolu kesimleri için kullanılan indeksi, $C$ ise $i$. devlet karayolu kesimindeki beş yıllık toplam ÖY kaza, ölü veya yaralı sayısını göstermektedir. Taşıt-km ise $i$. devlet karayolu kesimindeki beş yıllık toplam taşıt-km değerini, $R$ ise $i$. devlet karayolu kesiminde milyar taşıt-km'deki ÖY kaza, yaralanma ve ölüm sayısını göstermektedir.

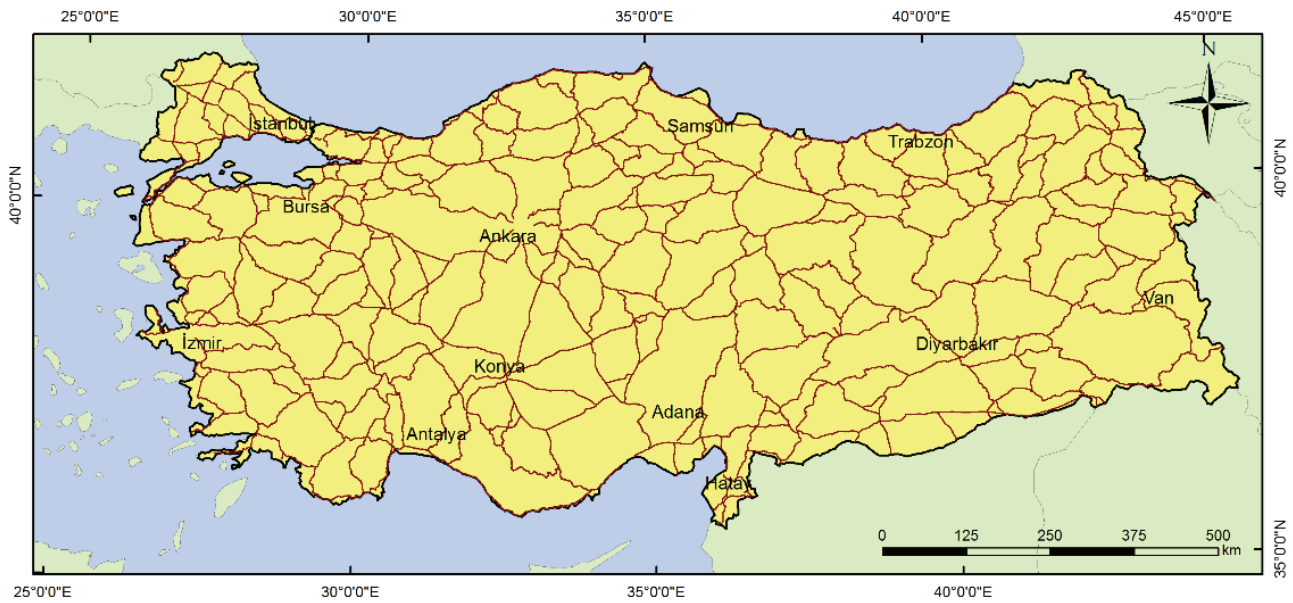

Şekil 1. Türkiye devlet karayolu ăg

Yukarıda belirtilen kaza oranlarına ek olarak, her bir devlet karayolu kesimindeki Yıllık Ortalama Günlük Trafik (YOGT), Yıllık Ortalama Günlük Ağır Taşıt Trafik (YOGATT), taşıt-km, ağır taşıt-km ve ağır taşıt yüzdesi (\%AT) gibi değişkenlerle kaza sayıları ve kaza oranları arasındaki korelasyonlar hesaplanarak kazalarda etkili olan faktörler belirlenmeye çalışılmıştır. Bir sonraki aşamada global Moran's I değeri hesaplanarak kaza oranlarının mekânsal korelasyonunun olup olmadığına bakılmıştır. Moran 's I değeri -1 ile 1 aralığında değişir. Pozitif Moran's I değeri benzer değerlerin kümelenmesini, negatif Moran's I değeri ise benzer olmayan değerlerin kümelenmesini gösterir. 0 değeri ise herhangi bir kümelenme olmadığını gösterir. Moran's I değeri aşağıdaki denklem ile hesaplanmaktadır [33].

$\mathrm{I}=\frac{N \sum_{i=1}^{N} \sum_{j=1}^{N} W_{i j}\left(X_{i}-\bar{X}\right)\left(X_{j}-\bar{X}\right)}{\left(\sum_{i=1}^{N} \sum_{j=1}^{N} W_{i j}\right)\left(\sum_{i=1}^{N}\left(X_{i}-\bar{X}\right)^{2}\right)}$

$\mathrm{Bu}$ denklemde, $\bar{X}$ değişkenin ortalamasını, $X_{i}$ değişkenin bir noktadaki değerini, $X_{j}$ değişkenin diğer bir noktadaki değerini, $W_{i j}$ ise $i$ ve $j$ noktalarının göreceli konumları arasındaki mekânsal ağırlığı ifade etmektedir. Moran's I değerinin istatistiksel olarak anlamlı olup olmadığını gösteren Z-skoru değeri ise aşağıdaki denklem ile hesaplanmaktadır. 
$\mathrm{Z}=\frac{I-E(I)}{\sqrt{V(I)}}$

$E(I)$ değeri I'nın beklenen değerini ifade etmektedir ve $-1 /(N-1)$ 'e eşittir. $V(I)$ ise $I$ değerinin varyansını göstermektedir. Moran's I değeri kaza oranı yüksek değerlerin mi yoksa kaza oranı düşük değerlerin mi kümelendiği bilgisini vermez. Herhangi bir kümelenme görülmesi durumunda kümelenmenin türünü belirlemek için General $G$ istatistiğine bakılması gerekir. Olası kümelenmelerin yerlerini belirlemek için ise yerel Moran's I analizinin yapılması gerekmektedir.

\section{BULGULAR}

Çalışmada incelenen 2009-2013 döneminde, her bir yılda meydana kazaların coğrafi koordinatlarının yol ağına atanması sonucunda devlet karayollarına düşen ÖY kaza sayısı, bu kazalardaki ölüm ve yaralanmalar Tablo 2'de gösterilmiştir. Bu tabloda ayrıca Coğrafi Bilgi Sistemleri ortamında yapılan bu atamanın güvenilirliğini sınamak için TÜİK tarafından devlet karayolları için yayınlanmış bütünleşik kaza istatistikleri de sunulmuştur [31]. Bu çalışmada kullanılan yöntem ile elde edilen sonuçlar TÜİK tarafindan yayınlanan değerlere oldukça yakındır. Aradaki küçük farklar muhtemelen kaza koordinatlarının atanması sırasında kullanılan yöntemsel farklılıklardan kaynaklanmaktadır. TÜİK ölümlü ve/veya yaralanmalı kazaları birlikte yayınladığı için ölümlü kazaların sayısı ancak bu çalışmada önerilen yöntem ile elde edilebilmektedir. TÜİK verileri bütünleşik olduğu için yıllık toplam ÖY kaza, ölü ve yaralı sayısını sunmaktadır. Bu çalışmada ise kazaların hangi yol kesimlerinde olduğu saptanmaya çalışıldığından, kaza koordinat verileri Coğrafi Bilgi Sistemleri ortamında yol kesimlerine atanmış ve hem kesim bazında hem de yıl bazında detaylı kaza sayıları elde edilmiştir.

Tablo 2. Yıllara göre devlet karayollarındaki ÖY kaza sayıları [31]

\begin{tabular}{|c|c|c|c|c|c|c|c|}
\hline \multirow[b]{2}{*}{ Y1l } & \multicolumn{4}{|c|}{ Bu çalışmada hesaplanan } & \multicolumn{3}{|c|}{ TÜİK } \\
\hline & $\begin{array}{c}\text { Ölümlü } \\
\text { Kaza }\end{array}$ & $\begin{array}{c}\text { ÖY } \\
\text { Kaza }\end{array}$ & Ölü & Yaralı & $\begin{array}{c}\text { ÖY } \\
\text { Kaza }\end{array}$ & Ölü & Yaral1 \\
\hline 2009 & 1.351 & 27.567 & 1.780 & 58.505 & 27.063 & 1.903 & 60.831 \\
\hline 2010 & 1.197 & 28.767 & 1.583 & 61.100 & 27.175 & 1.685 & 63.447 \\
\hline 2011 & 1.199 & 32.398 & 1.590 & 67.765 & 30.975 & 1.649 & 69.248 \\
\hline 2012 & 1.171 & 33.383 & 1.523 & 70.099 & 33.045 & 1.617 & 72.571 \\
\hline 2013 & 1.281 & 36.461 & 1.620 & 72.987 & 35.068 & 1.731 & 77.121 \\
\hline Toplam & 6.199 & 149.151 & 8.096 & 330.456 & 154.326 & 8.585 & 343.218 \\
\hline Ortalama & 1.240 & 29.830 & 1.619 & 66.091 & 30.865 & 1.717 & 68.643 \\
\hline
\end{tabular}

Türkiye'de 708 kesimden meydana gelen devlet karayollarının toplam uzunluğu 31.341 km'dir. Bu kesimlerin uzunlukları 2 km'den 106 km'ye kadar değişmekte olup, ortalama kesim uzunluğu 45 km'dir. Tablo 2'de görüldüğü gibi 2009 ile 2013 yılları arasında devlet 
karayollarında yılda ortalama 1.240 ölümlü kazada 1.619 kişi ölmektedir. Toplam 708 kesimde gerçekleşen kazalar, kesim başına yılda (5 yıllık ortalama) 1,75 ölümlü kaza olduğunu göstermektedir. Bazı kesimlerin bu ortalamadan yüksek, bazılarının ise düşük olması kazaların coğrafi dağılımının incelenmesini gerektirmektedir. Yapılan analizler bu kesimlerin yaklaşık yarısında yıl içerisinde herhangi bir ölümlü kaza yaşanmadığını göstermiştir. Kesim düzeyinde bu kadar küçük değerlerle yapılacak karşılaştırmanın hatalı yorumlara yöneltebileceği gerçeğinden yola çıkılarak bu çalışmada öncelikli olarak ÖY kazalara odaklanılmıştır.

Tablo 3'de bu çalışmada önerilen yöntem ile hesaplanan devlet karayollarında milyar taşıtkm'deki ÖY kaza, ölüm ve yaralanma sayıları gösterilmiştir. Hesaplamalarda kullanılan devlet karayollarındaki taşıt-km değerleri, Karayolları Genel Müdürlüğü (KGM) tarafından her yıl kesim düzeyinde detaylı olarak yayınlanan trafik ve ulaşım bilgilerinden alınmıştır [34]. Tablo 3 incelendiğinde, 2009 ile 2013 yılları arasında devlet karayollarında milyar taşıtkm'de yılda ortalama 520 ÖY kaza meydana geldiği ve bu kazalarda 26,6 kişinin öldüğü, 1.084 kişinin yaralandığı görülmektedir. Devlet karayollarındaki milyar taşıt-km'deki ölümler ciddi biçimde azalmakta olup, yaralanmalar ise yıllar arasında belirgin bir değişim göstermemektedir. Milyar taşıt-km'deki ölüm sayılarındaki düşüşte devlet karayollarındaki bölünmüş yol oranının artmış olmasının etkisi muhtemeldir. Milyar taşıt-km'deki ÖY kaza sayısında ise 2010 yılı sonrası bir miktar artış göze çarpmaktadır. Her ne kadar 2010 sonrası elimizde kesin bir yargıya varmaya yetecek kadar yıl verisi olmasa da, bu artışta 2010 yılında bölünmüş devlet karayollarındaki hız sınırının 90 km/s'den $110 \mathrm{~km} / \mathrm{s}$ 'e yükseltilmesinin etkisi olması muhtemeldir. Bu iki nokta trafik güvenliği açısından incelenmesi gereken konular arasında olmasına rağmen henüz detaylı olarak incelenmemiştir.

Tablo 3. Devlet karayollarında milyar taşıt-km'deki ÖY kaza, ölü ve yaralı sayıları

\begin{tabular}{lccccc}
\hline Y1l & $\begin{array}{c}\text { ÖY } \\
\text { Kaza }\end{array}$ & $\begin{array}{c}\text { Milyar } \\
\text { Taşıt-km }\end{array}$ & $\begin{array}{c}\text { ÖY/Milyar } \\
\text { Taşıt-km }\end{array}$ & $\begin{array}{c}\text { Ölü/Milyar } \\
\text { Taşıt-km }\end{array}$ & $\begin{array}{c}\text { Yaralı/Milyar } \\
\text { Taşıt-km }\end{array}$ \\
\hline 2009 & 27.567 & 51,9 & 531 & 34,3 & 1.127 \\
2010 & 28.767 & 58,2 & 494 & 27,2 & 1.050 \\
2011 & 32.398 & 62,2 & 521 & 25,6 & 1.089 \\
2012 & 33.383 & 64,6 & 525 & 23,6 & 1.085 \\
2013 & 36.461 & 68,0 & 536 & 23,8 & 1.073 \\
Ortalama & 31.715 & 61,0 & 520 & 26,6 & 1.084 \\
\hline
\end{tabular}

Tablo 4'de devlet karayollarındaki ÖY kazaları etkileyen faktörleri tespit etmek için kesim düzeyinde hesaplanan korelasyon katsayıları görülmektedir. Bu analizde,

- Her bir kesimdeki 5 yıllık ortalama YOGT, YOGATT, taşıt-km, ağır taşıt-km, \%AT ile yine her bir kesimdeki 5 yıllık ortalama ÖY kaza, ölü ve yaralı sayıları arasındaki korelasyon katsayıları, 
- Her bir kesimdeki 5 yıllık ortalama YOGT, YOGATT, taşıt-km, ağır taşıt-km, \%AT ile her bir kesim için Denklem 1 kullanılarak hesaplanan milyar taşıt-km'deki ÖY kaza, ölü ve yaralı sayıları arasındaki korelasyon katsayıları hesaplanmıştır.

Tablo 4. Devlet karayollarında ÖY kaza, ölüm ve yaralanmalara etki eden faktörler

\begin{tabular}{lccccccc}
\hline \multirow{2}{*}{ Değişken } & \multicolumn{3}{c}{ Say1 } & & \multicolumn{3}{c}{ Milyar taşıt-km'deki } \\
\cline { 2 - 3 } \cline { 7 - 8 } & ÖY & Kälü & Yaralı & & $\begin{array}{c}\text { ÖY } \\
\text { Kaza }\end{array}$ & Ölü & Yaralı \\
\hline YOGT & 0,69 & 0,53 & 0,64 & & $-0,03$ & $-0,02$ & $-0,06$ \\
YOGATT* & 0,58 & 0,62 & 0,60 & & $-0,02$ & 0,07 & 0,03 \\
Taşıt-km & 0,84 & 0,70 & 0,80 & & $-0,01$ & 0,01 & $-0,03$ \\
Ağır taşıt-km* & 0,72 & 0,79 & 0,77 & & 0,00 & 0,10 & 0,00 \\
\%AT* & $-0,09$ & 0,12 & $-0,02$ & & $-0,08$ & 0,19 & 0,03 \\
\hline
\end{tabular}

* Ağır taşıtlar kamyonları, kamyon+römorkları, çekici+yarı römorkları ve otobüsleri içermektedir.

Hesaplamalarda kullanılan her bir devlet karayolu kesimindeki YOGT, YOGATT, taşıt-km, ağır taşıt-km ve \%AT verileri her yıl düzenli olarak KGM tarafından yayınlanan istatistiklerden alınmıştır [34]. Her bir kesimdeki ÖY kaza, ölü ve yaralı sayıları ise bu çalışma kapsamında kazaların coğrafi koordinatlarının yol ağına atanması sonucunda elde edilmiştir. Devlet karayolu kesimlerindeki ortalama hız verileri düzenli ve güvenilir bir şekilde yayınlanmadığı için bu çalışma kapsamında hız ile ilgili bir korelasyon analizi yapılamamıştır. Kesim düzeyindeki korelasyon analizin sonuçları aşağıda özetlenmiştir:

- ÖY kaza sayıları ile YOGT, taşıt-km ve ağır taşıt-km arasında yüksek korelasyon bulunmuştur. ÖY kaza sayıları ile YOGATT arasındaki korelasyon bir miktar daha düşüktür.

- Ölü sayıları ile taşıt-km ve ağır taşıt-km arasında yüksek korelasyon bulunmuştur. Ölü sayıları ile YOGATT arasındaki korelasyon yükseğe yakındır.

- Yaralı sayıları ile taşıt-km ve ağır taşıt-km arasında yüksek korelasyon bulunmuştur. Yaralı sayıları ile YOGT ve YOGATT arasındaki korelasyon yükseğe yakındır.

- Milyar taşıt-km'deki ÖY kaza, ölü ve yaralı sayıları ile seçilen değişkenler arasında anlamlı korelasyonlar bulunamamıştır.

- \%AT ile ilgili anlamlı korelasyonlar bulunamamıştır.

Bu değerlere bakarak, devlet karayolu kesimlerindeki ÖY kaza, ölü ve yaralı sayılarında, kesimlerdeki taşıt-km değerlerinin (taşıt-km ve ağır taşıt-km) taşıt sayılarından (YOGT ve YOGATT) daha etkili olduğu yorumu yapılabilir. YOGATT ve ağır taşıt-km ile ilgili korelasyonlar yüksek çıkarken, \%AT ile ilgili korelasyonların düşük çıkması ise ÖY kaza, ölü ve yaralı sayılarında kesimlerdeki ağır taşıt yüzdesi yerine ağır taşıt sayısının etkili olduğunun göstergesidir. 


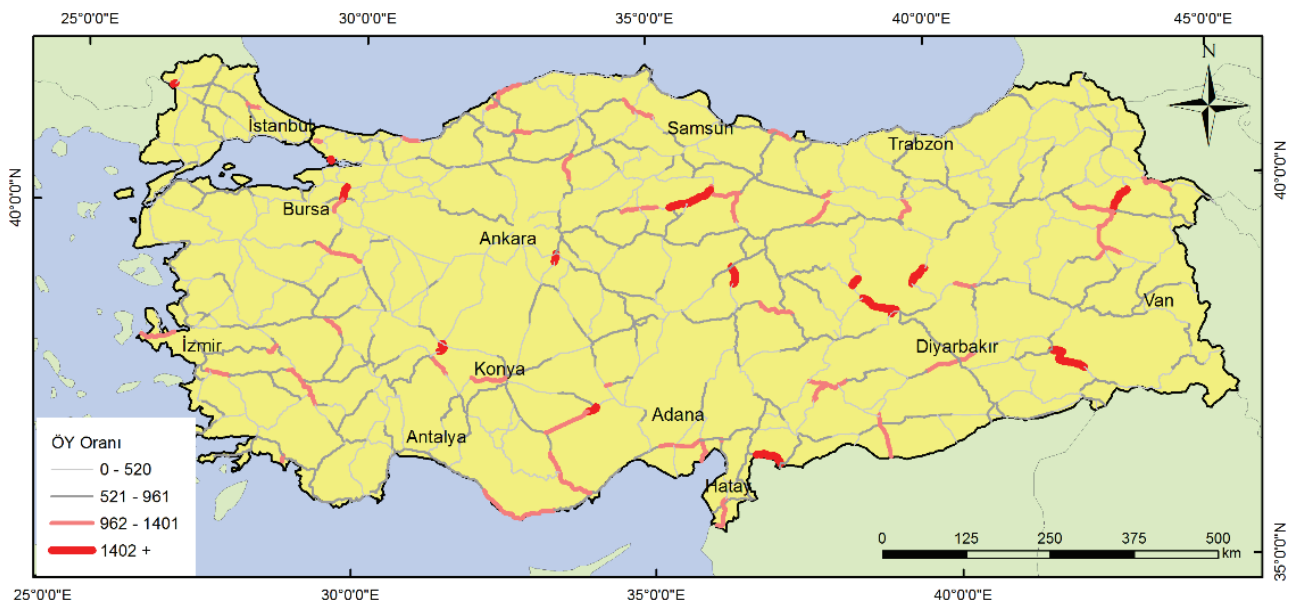

Şekil 2. Devlet karayolu kesimlerinde milyar taşıt-km'deki ÖY kaza sayıları

Tablo 5. Milyar taşıt-km'deki ÖY kaza sayısı en yüksek 20 devlet karayolu kesimi

\begin{tabular}{lcccrrrc}
\hline İl & $\begin{array}{c}\text { Uzunluk } \\
(\mathrm{km})\end{array}$ & $\begin{array}{c}\text { Bölünmüş } \\
\text { Yol }\end{array}$ & $\begin{array}{c}\text { Milyon } \\
\text { Taşıt-km }\end{array}$ & $\begin{array}{c}\text { ÖY } \\
\text { Kaza }\end{array}$ & Ölü & Yaralı & $\begin{array}{c}\text { ÖY/Milyar } \\
\text { Taşı-km }\end{array}$ \\
\hline Edirne & 4 & Hayır & 4,8 & 32 & 1 & 45 & 6.742 \\
Konya & 19 & Hayır & 27,6 & 81 & 0 & 129 & 2.939 \\
Konya & 15 & Hayır & 55,8 & 152 & 0 & 226 & 2.725 \\
Ağrı & 48 & Hayır & 32,8 & 78 & 2 & 97 & 2.378 \\
Elazı̆̆ & 70 & Hayır & 137,4 & 326 & 2 & 578 & 2.373 \\
Gaziantep & 47 & Hayır & 110,1 & 203 & 10 & 388 & 1.844 \\
Malatya & 18 & Hayır & 12,6 & 23 & 1 & 38 & 1.824 \\
Sivas* & 31 & 2013 & 32,3 & 55 & 3 & 154 & 1.704 \\
Tunceli & 38 & Hayır & 115,8 & 194 & 4 & 385 & 1.675 \\
Tokat & 62 & Hayır & 195,8 & 328 & 7 & 538 & 1.675 \\
Kırıkkale & 13 & 2013 & 7,3 & 12 & 0 & 31 & 1.654 \\
Siirt & 85 & Hayır & 208,2 & 309 & 6 & 587 & 1.484 \\
Kocaeli & 3 & Hayır & 88,4 & 126 & 1 & 267 & 1.426 \\
Bursa & 23 & Hayır & 102,8 & 146 & 2 & 235 & 1.420 \\
Bingöl & 36 & Evet & 197,6 & 275 & 10 & 648 & 1.392 \\
İstanbul* & 12 & 2013 & 438,2 & 607 & 12 & 986 & 1.385 \\
Osmaniye & 2 & Hayır & 14,5 & 20 & 0 & 55 & 1.384 \\
Gümüşhane & 44 & Hayır & 101,5 & 140 & 20 & 377 & 1.380 \\
Aydın & 35 & Evet & 601,9 & 829 & 25 & 1441 & 1.377 \\
Adana & 37 & Hayır & 186,8 & 257 & 5 & 349 & 1.376 \\
\hline$* 2013$ yl & 13 & & & & & \\
\hline
\end{tabular}

*2013 y1lında bölünmüş yol haline gelmiştir. 
Devlet karayolu kesimlerindeki milyar taşıt-km'deki ÖY kaza sayıları Şekil 2'de gösterilmiştir. $\mathrm{Bu}$ tematik harita oluştururken ortalamanın altındaki kesimler $(\mathrm{R}<520)$, ortalamanın bir standart sapmaya kadar üzerindeki kesimler $(\mathrm{R}<520+440)$, ortalamanın iki standart sapmaya kadar üzerindeki kesimler $(\mathrm{R}<520+2 * 440)$ ve kaza oranı daha büyük kesimler şeklinde dört grup oluşturulmuştur. Moran's I analizi sonuçları devlet karayolu kesimlerindeki milyar taşıt-km'deki ÖY kaza sayılarının 0,05 güvenilirlik düzeyinde anlamlı bir şekilde kümelenmediğini ve rastgele dağıldığını göstermiştir (I: 0,05; Z-skor: 1,81 ve pdeğeri: 0,07). General $G$ istatistiği sonuçları da milyar taşıt-km'deki ÖY kaza sayıları yüksek ve düşük bölgelerin rastgele dağıldığını göstermiştir (General G: 0,00; Z-skor: 0,12 ve pdeğeri: 0,91). Tablo 5'de milyar taşıt-km'de ÖY kaza sayısı en yüksek 20 kesime ait bilgiler listelenmiştir. Bu tablodaki taşıt-km, ÖY kaza, ölü ve yaralı sayıları 2009-2013 arasındaki toplam değerleri göstermektedir. Görüldüğü gibi bu kesimlerin neredeyse hepsi bölünmemiş karayoludur ve uzunlukları oldukça değişkenlik göstermektedir.

\section{SONUÇLAR VE TARTIŞMA}

Bu çalışmada Türkiye'de devlet karayolu kesimlerinde 2009 ile 2013 yılları arasında meydana gelen kazaların mekânsal analizi yapılmıştır. Her bir kesime ulusal düzeyde karşılaştırma yapabilecek kadar yeteri miktarda kaza düşmesini sağlamak amacıyla ÖY kazalara yoğunlaşılmıştır. Kaza analizlerinde literatürde en yaygın gösterge olarak kullanılan milyar taşıt-km'deki kaza sayısı kullanılmıştır. Yapılan analizler devlet karayollarında milyar taşıt-km'de ortalama 520 ÖY kaza meydana geldiğini, bu kazalarda 26,6 kişinin öldüğünü ve 1.084 kişinin yaralandığını göstermiştir. Bu değerlere bakıldığında devlet karayollarındaki trafik güvenliğinin Türkiye ortalamasından daha iyi seviyede olduğu görülmektedir. Daha yüksek hizmet seviyesine göre tasarlanmış devlet karayollarında trafik güvenliğinin daha iyi olması istenen bir sonuçtur.

Kesim düzeyinde yapılan korelasyon analizleri sonucunda kesimlerdeki ÖY kaza, ölü ve yaralı sayılarında taşıt-km değerlerinin (taşıt-km ve ağır taşıt-km) taşıt sayısından (YOGT ve YOGATT) daha etkili olduğu görülmüştür. Ayrıca, ÖY kaza, ölü ve yaralı sayılarında kesimlerdeki ağır taşıt yüzdesinin etkili bir faktör olmadığı, ağır taşıtlar sayısının ise etkili bir faktör olduğu görülmüştür.

Kazaların coğrafi dağılımı incelendiğinde Türkiye'deki devlet karayollarında dağınık bir örüntü (kümelenme olmadığı) tespit edilmiştir. Bu sonuçlar belirli bölgeler ya da koridorlarda değil, yol ağının sadece belirli kesimlerinde ÖY kaza oranının oransal olarak daha yüksek olduğunu göstermektedir. Dolayısıyla yol altyapısının yeterliliği ve buna bağlı olarak trafik güvenliği açısından bölgeler arasında bir dengesizlik bulunmamaktadır. Belirli bir bölgede yoğunlaşma altyapı yatırımlarının dengesiz dağıldığını işaret eder. Mevcut durum ise iki farklı sonucu işaret etmektedir:

Birincisi, belirli bölgelerde yoğunlaşma olmamakla beraber kaza oranları birden fazla bölgeyi birleştiren koridorlar bazında yüksek çıkabilir. Kaza yoğunluk haritası incelendiğinde böyle bir dağılım ortaya çıkmamaktadır. Bu şekilde bir sonuç çıksaydı belirli bölgelerde altyapının yetersiz olduğu, ya da yol güvenliğinin yeterince sağlanamadığı sonucuna varılabilirdi. Böyle bir durum, yol yatırım ve iyileştirme önceliklerinde bölgeler arasında öncelik sıralamasını gerektirirdi. Ancak bulgular, taşıt hacimleri açısından bazı bölgelerdeki (Marmara, Ege, Çukurova) belirli koridorların 
yoğun olmakla beraber bu bölgelerdeki yollarda trafik güvenliği açısından diğer bölgelerden daha olumsuz sonuçların olmadığını göstermektedir.

İkinci durum ise kaza yoğunluğu yüksek olan yol kesimlerinin belirli bölge ya da koridorlarda yoğunlaşmadan ülke genelinde dağınık olmasıdır ki elde edilen sonuçlar bu şekildedir. Dolayısıyla her bölgede belirli sayıda yol kesimi trafik güvenliği (kaza oranı) açısından yüksek risk taşımaktadır. Bu sonuç her bölgede sadece sorunlu yol kesinlerine odaklanılarak çözümler geliştirilmesinin daha etkili sonuçlar vereceğini (kaza oranlarının düşürülebileceğini) göstermektedir.

Ülke genelinde karayolu ağında kaza oranlarının en yüksek olduğu 20 yol kesimi bütün bölgelere dağılmış durumdadır. Bu yollarda kaza oranlarının yüksek olma nedenleri aşağıdaki olasılıklarla açıklanabilir:

Kaza oranlarının en yüksek olduğu bu yol kesimlerinin tamamına yakını bölünmemiş yoldur. Bölünmüş yol yatırım kararlarında sadece taşıt hacminin değil kaza oranının da bir etken olarak değerlendirilmesi gerekmektedir. Böylece kaza oranları azaltılabilir.

Kaza oranlarının yüksek olduğu her bir yol kesiminin geometrik özellikleri (dönemeç yarıçapları, eğim, şerit genişliği, güvenlik şeridi vd.) standartlara uygun olmayabilir. Bu etkenin ne düzeyde etkili olduğunun saptamak için her kesim için detaylı saha çalışmasının yapılması bundan sonraki çalışmalar için önerilmektedir.

$\mathrm{Bu}$ yol kesimlerinde kavşakların aralıkları ve geometrik ölçüleri standartlara uygun olmaması yüksek kaza oranlarının nedenlerinden bir tanesi olabilir. Dolayısıyla kaza oranlarının yüksek olduğu kesimlerde kavşak konumlarının incelenmesi ve gerektiği taktirde kavşak tasarımlarının iyileştirilmesi kaza sayısı ve oranının düşürülmesinde etkili bir önlem olabilir.

Kaza oranlarının yüksek olduğu kesimlerinde ortalama taşıt hızları, ağır taşıt trafiği ve bu taşıtların karıştığ 1 kazalar ve iklimsel koşullar yüksek kaza oranlarına etki edebilecek diğer faktörler arasındadır. Bu faktörlerin etkinin incelenmesi için detaylı saha çalışması ve istatistiksel analizler bundan sonraki çalışmalar için önerilmektedir.

Yukarıda sıralanan etkenleri kapsayan analizler sonrasında kazaların en yüksek oranda görüldüğü karayolu kesimlerinde yeni yatırım, iyileştirme, bakım ve önlemlerin alınması için yeterli düzeyde bilimsel dayanak oluşturulabilir. Bu yöndeki çalışmalar kamunun önemli düzeyde kaynak ayırdığı karayolu altyapı yatırımlarının sadece talebe (ya da taşıt hacmine) göre değil aynı zamanda trafik güvenliğini (can ve mal kayıplarının ve yaralanmaların azaltılması) esas alarak planlanması ve gerçekleştirilmesi ile sağlanabilir. Bununla birlikte trafik kazalarına etki eden faktörlerin daha detaylı olarak analiz edilmesi gerekmektedir. $\mathrm{Bu}$ durum kaza verilerinin daha detaylı bir şekilde toplanmasıyla mümkün olabilir. Bu sağlandığı takdirde belirli taşıt hatta belirli çarpışma tipine bağlı kazalar bile detaylı olarak incelenebilecek ve bunları önleyebilecek stratejiler geliştirilebilecektir.

\section{Semboller}

C : Devlet karayolu kesimindeki 5 yıllık toplam ÖY kaza, ölü veya yaralı sayısı

i : Devlet karayolu kesim indeksi 
ÖY : Ölümlü ve/veya yaralanmalı kaza

R : Devlet karayolu kesimindeki milyar taşıt-km’deki ÖY kaza, ölü veya yaralı sayis1

TÜİK : : Türkiye İstatistik Kurumu

YOGATT: Yıllık Ortalama Günlük Ağır Taşıt Trafik

YOGT : Y1llık Ortalama Günlük Trafik

\%AT : Ağıt Taşıt Yüzdesi

\section{Kaynaklar}

[1] Lozano, R.,Naghavi, M., Foreman, K., Lim, S., Shibuya, K., Aboyans, V., ... ve AlMazroa, M. A., Global and Regional Mortality From 235 Causes of Death for 20 Age Groups in 1990 and 2010: A Systematic Analysis For The Global Burden Of Disease Study 2010. The Lancet, 380(9859), 2095-2128, 2013.

[2] World Health Organization. Violence, Injury Prevention\& World Health Organization. Global Status Report on Road Safety 2013: Supporting a Decade of Action, Luxemburg. World Health Organization, 2013.

[3] Mathers, C., Fat, D. M. ve Boerma, J. T. The Global Burden of Disease: 2004 Update, Switzerland. World Health Organization, 2008.

[4] Türkiye İstatistik Enstitüsü. Karayolu Trafik Kaza İstatistikleri, 2015. Türkiye, 2016. http://www.tuik.gov.tr/PreHaberBultenleri.do?id=21611

[5] Türkiye İstatistik Enstitüsü. Motorlu Kara Taşıtları, Aralık 2015. Türkiye, 2016. http://www.tuik.gov.tr/PreHaberBultenleri.do?id=21600

[6] Türkiye İstatistik Enstitüsü. Temel İstatistikler: Nüfus ve Demografi. Türkiye, 2016. http://www.tuik.gov.tr/UstMenu.do?metod=temelist

[7] Organisation for Economic Co-operation and Development/International Transport Forum. Road Safety Annual Report 2016, Paris. OECD Publishing, 2016.

[8] European Commission. Road Safety Evolution in the EU by Population. 2016. http://ec.europa.eu/transport/road_safety/pdf/observatory/historical_evol_popul.pdf

[9] Türkiye Karayolları Genel Müdürlüğü. Stratejik Plan 2012-2016. Türkiye, 2015. http://www.kgm.gov.tr/SiteCollectionDocuments/KGMdocuments/Kurumsal/Strateji kPlan/sp12_16.pdf

[10] Khattak, A. J., Schneider, R. J. ve Targa, F., Risk Factors in Large Truck Rollovers and Injury Severity: Analysis of Single-Vehicle Collisions. In Proceedings of theTransportation Research Board 82nd Annual Conference, Washington, D.C., 2003.

[11] Khorashadi, A., Niemeier, D., Shankar, V. ve Mannering, F., Differences in Rural and Urban Driver-Injury Severities in Accidents Involving Large-Trucks: An Exploratory Analysis. Accident Analysis \& Prevention, 37(5), 910-921, 2005. 
[12] Savolainen, P., Mannering, F., Probabilistic Models of Motorcyclists' Injury Severities in Single-And Multi-Vehicle Crashes. Accident Analysis \& Prevention, 39(5), 955963, 2007.

[13] Kockelman, K. M., Kweon, Y. J., Driver Injury Severity: An Application of Ordered Probit Models. Accident Analysis \& Prevention, 34(3), 313-321, 2002.

[14] Gray, R. C., Quddus, M. A.,ve Evans, A., Injury Severity Analysis of Accidents Involving Young Male Drivers in Great Britain. Journal of Safety Research, 39(5), 483495, 2008.

[15] Khattak, A., Luo, Z.veGao, M., Investigation of Factors Associated with Truck Crash Severity in Nebraska. Report 25-1121-0001-104, 2012.

[16] Chang, L. Y., Chien, J. T., Analysis of Driver Injury Severity in Truck-Involved Accidents Using a Non-Parametric Classification Tree Model. Safety science, 51(1), 17-22, 2013.

[17] Dong, C., Richards, S. H., Huang, B., ve Jiang, X., Identifying the Factors Contributing to the Severity of Truck-Involved Crashes. International Journal of Injury Control and Safety Promotion, 22(2), 116-126, 2015.

[18] Erdogan, S., Explorative Spatial Analysis of Traffic Accident Statistics and Road Mortality among the Provinces of Turkey. Journal of Safety Research, 40(5), 341-351, 2009.

[19] Erdogan, S.,Yilmaz, I., Baybura, T. ve Gullu, M., Geographical Information Systems Aided Traffic Accident Analysis System Case Study: City of Afyonkarahisar. Accident Analysis \& Prevention, 40(1), 174-181, 2008.

[20] Murat, Y. Ş., Şekerler, A., Trafik Kaza Verilerinin Kümeleme Analizi Yöntemi ile Modellenmesi. Teknik Dergi, 20(98), 2009.

[21] Keskin, F., Yenilmez, F., Çolak, M., Yavuzer, I. ve Düzgün, H. S., Analysis of Traffic Incidents in METU Campus. Procedia-Social and Behavioral Sciences, 19, 61-70, 2011.

[22] Kundakci, E., Tuydes-Yaman, H., Understanding the Distribution of Traffic Accident Hotspots in Ankara, Turkey. In Proceedings of the In Proceedings of the Transportation Research Board 93rd Annual Conference, Washington, D.C., 2014.

[23] Kaygisiz, Ö., Düzgün, Ş., Yildiz, A. ve Senbil, M., Spatio-Temporal Accident Analysis for Accident Prevention in Relation to Behavioral Factors in Driving: The Case of South Anatolian Motorway. Transportation Research Part F: Traffic Psychology and Behaviour, 33, 128-140, 2015.

[24] Erdogan, S., Ilçı, V., Soysal, O. M. ve Kormaz, A., A Model Suggestion for the Determination of the Traffic Accident Hotspots on the Turkish Highway Road Network: A Pilot Study. Boletim de Ciências Geodésicas, 21(1), 169-188, 2015.

[25] Celik, A. K., Oktay, E., A Multinomial Logit Analysis of Risk Factors Influencing Road Traffic Injury Severities in The Erzurum and Kars Provinces of Turkey. Accident Analysis \& Prevention, 72, 66-77, 2014. 
[26] Uçar, Ö.,Tatlıdil, H., Factors Influencing the Severity of Damage in Bus Accidents in Turkey during 2002: A Application of the Ordered Probit Model. Hacettepe Journal of Mathematics and Statistics, 36(1), 2007.

[27] Baker, S. P.,Whitfield, R. A. ve O'Neill, B., Geographic Variations in Mortality from Motor Vehicle Crashes. New England Journal of Medicine, 316(22), 1384-1387, 1987.

[28] Fridstrøm, L. ve Ingebrigtsen, S., An Aggregate Accident Model based on Pooled, Regional Time-Series Data. Accident Analysis \& Prevention, 23(5), 363-378, 1991.

[29] Van Beeck, E. F.,Mackenbach, J. P., Looman, C. W., ve Kunst, A. E., Determinants of Traffic Accident Mortality in The Netherlands: A Geographical Analysis. International Journal of Epidemiology, 20(3), 698-706, 1991.

[30] Aguero-Valverde, J., ve Jovanis, P. P., Spatial Analysis of Fatal and Injury Crashes in Pennsylvania. Accident Analysis \& Prevention, 38(3), 618-625, 2006.

[31] Türkiye İstatistik Enstitüsü. Trafik Kaza İstatistikleri - Karayolu, 2009-2013. Türkiye İstatistik Enstitüsü. Türkiye, 2016.

[32] Türkiye Karayolları Genel Müdürlüğü. Karayolları Üzerindeki Seyir ve Taşımalar. Türkiye, 2016.

http://www.kgm.gov.tr/SiteCollectionDocuments/KGMdocuments/Istatistikler/Seyirv eTasimalar/SeyirVeTasimalar.pdf

[33] Moran, P.A.P., Notes on Continuous Stochastic Phenomena, Biometrika 37, 17-23, 1950.

[34] Türkiye Karayolları Genel Müdürlügü. Trafik ve Ulaşım Bilgileri. Türkiye, 2016. http://www.kgm.gov.tr/Sayfalar/KGM/SiteTr/Istatistikler/TrafikveUlasim.aspx 